\title{
LOMAC Regimen
}

National Cancer Institute

\section{Source}

National Cancer Institute. LOMAC Regimen. NCI Thesaurus. Code C161975.

A chemotherapy regimen consisting of cyclophosphamide, doxorubicin, vincristine, and methotrexate with leucovorin that may be used in the treatment of breast cancer. 